\title{
A Territorialidade e o Território na Obra de Robert David Sack
}

\author{
Territoriality and Territory in the Work of Robert David Sack
}

La Territorialidad y el Territorio en la Obra de Robert David Sack

Amilton Quintela Soares Junior ${ }^{1}$
Mauro Augusto dos Santos

\begin{abstract}
RESUMO: Um dos autores mais citados em trabalhos científicos que abordam a temática territorial, Robert David Sack é constantemente mencionado, de maneira superficial, com base nos conceitos iniciais de território e territorialidade humana apresentados em Human Territoriality: Its theory and history. A obra, que ainda não foi traduzida oficialmente para o português, é o foco do presente artigo, que busca produzir uma síntese da teoria de Sack e uma relação entre seus conteúdos e a visão de outros autores, explorando aspectos potencialmente mais profundos e demonstrando a sua importante contribuição para a compreensão da territorialidade como estratégia espacial de controle e influência, capaz de produzir efeitos e combinações de efeitos que impactam diretamente as relações entre as pessoas e os fenômenos que se manifestam em um território.
\end{abstract}

PALAVRAS-CHAVE: Robert David Sack. Território. Territorialidade.

ABSTRACT: One of the most quoted authors in scientific papers that deal with territorial issues, Robert David Sack is constantly mentioned superficially, based on the initial concepts of territory and human territoriality presented in Human Territoriality: Its theory and history. This work, not yet officially translated for Portuguese, is the focus of this article, which seeks to produce a synthesis of Sack's theory and a relationship between its contents and the view of other authors, exploring potentially deeper aspects of its content and demonstrating its important contribution to the understanding of territoriality as a spatial strategy of control and influence, capable to produce effects and combinations of effects that directly impact the relations between people and the phenomena that manifest themselves in a territory.

KEYWORDS: Robert David Sack. Territory. Territoriality.

RESUMEN: Uno de los autores más aludidos en trabajos científicos que plantean la temática territorial, Robert David Sack es constantemente mencionado, de manera superficial, basado en los conceptos iniciales de territorio y territorialidad humana presentados en Human Territoriality: Its theory and history. La obra, que todavía no fue traducida oficialmente al Portugués, es el foco del presente artículo, que busca producir una síntesis de la teoría de Sack y una relación entre sus contenidos y la visión de otros autores, explorando aspectos potencialmente más profundos de su contenido y demostrando su importante contribución para la comprensión de la territorialidad como estrategia espacial de control e influencia, capaz de producir efectos y combinaciones de efectos que impactan directamente las relaciones entre las personas y los fenómenos que se manifiestan en un territorio.

PALABRAS CLAVES: Robert David Sack. Territorio. Territorialidad.

\footnotetext{
${ }^{1}$ Fundação Presidente Antônio Carlos/UNIPAC - GV. Endereço: Rua Dr. Paulo de Souza Lima, 619, Cidade Nova, CEP: 35063-007, Governador Valadares - MG. amilton.soares@gmail.com.

2 Universidade Vale do Rio Doce (UNIVALE). Endereço: Rua Treze, 94/201, Santos Dumont I, CEP: 35022-160, Governador Valadares - MG. mauroasantos@gmail.com.
} 


\section{INTRODUÇÃO}

Território e territorialidade são conceitos abordados por diferentes correntes teóricas, a partir de diferentes perspectivas e dimensões. Positivistas, materialistas, estruturalistas e até mesmo as correntes mais voltadas à subjetividade lançam seus olhares sobre o território, que pode ser percebido, compreendido e avaliado a partir de várias facetas, daquelas mais direcionadas a questões específicas àquelas de caráter integrador, que buscam abarcar um maior contingente de variáveis de estudo.

Desse modo, o território pode ser desde o mero espaço físico (material), passando pela delimitação de superfície que integra natureza e ação humana, até uma representação simbólica que pode denotar vínculo ou pertencimento. O território pode ser um constante devir, um objeto em permanente construção, formado a partir de interações múltiplas e, assim, pode ser entendido como a esfera que possibilita a existência da multiplicidade, onde trajetórias diversas coexistem - como na visão de Massey (2008), que chega a criticar duramente, reputando como incompletas e limitadas, quaisquer outras tentativas de conceber ou explicar o território. Há, ainda, abordagens de caráter mais integrador, como as de Haesbaert $(2002,2003,2004,2007,2014)$ e Saquet $(2006,2007,2011)$, para os quais 0 território é uma combinação de estruturas naturais e produzidas, uma construção social, histórica, econômica, política, cultural e simbólica. Tal perspectiva representa bem a multidimensionalidade do conceito.

Há também as perspectivas impregnadas de subjetivismo, como a de Lepetit (2001), que percebe o território como um contexto dinâmico, caracterizado pelo movimento de temporalidades e escalaridades diversas, ou como as de Deleuze e Guatari (1992, 2005, 2010) e Guatarri e Rolnik (1996) que, com uma abordagem fenomenológica, apontam o desejo humano como fonte de criação dos territórios. Segundo Guatarri e Rolnik (1996), o território, sendo uma apropriação, é constituído por projetos e representações que levam a um repertório de comportamentos e investimentos realizados nos tempos e espaços cognitivos, estéticos, culturais e sociais.

Por outro lado, os territórios também podem constituir sistemas estruturados, compostos por processos relacionais, ora impregnados de poder, como apresenta Raffestin (1993), ora de técnica, como defende Milton Santos (2006).

$E$, sem querer estabelecer concordância ou refutação definitiva em relação a qualquer abordagem, o presente artigo destaca a perspectiva relacional e busca apresentar uma síntese da teoria de Robert David Sack, que nos apresenta o território como a área geográfica que resulta da aplicação de estratégias para afetar, influenciar e controlar pessoas, fenômenos e relações (SACK, 1986). 
Em Human Territoriality: Its theory and history, Sack (1986) apresenta conceitos de território e territorialidade humana que serão reproduzidos em um sem número de trabalhos de caráter científico que tratam de questões afeitas à temática territorial. Entretanto, ainda não há tradução oficial da obra e os conceitos de Sack são, muitas vezes, citados de maneira superficial. Geralmente, o conteúdo citado sempre se refere aos conceitos de territorialidade apresentados na própria introdução da obra de Sack ou no primeiro capítulo de Human Territoriality.

Desse modo, alguns dos aspectos mais relevantes e promissores da obra de Sack, no sentido de promover uma melhor compreensão da territorialidade humana como estratégia social para produzir influências e manifestar controle, bem como alguns dos elementos mais ricos e profundos da teoria do autor, como as tendências e combinações derivadas da aplicação da territorialidade por indivíduos e grupos, permanecem pouco explorados.

Assim, no sentido de descortinar pontos críticos da teoria de Sack, este artigo propõe uma síntese do conteúdo apresentado em Human Territoriality, notadamente do segundo capítulo da obra, na qual o autor apresenta suas reflexões e análises teóricas e conceituais sobre a territorialidade, seu uso intencional e seus efeitos.

\section{TERRITORIALIDADE - UMA ESTRATÉGIA INTENCIONAL DE UTILIZAÇÃO DO ESPAÇO}

Publicada em um momento marcado pelo ganho de relevância do conceito de território nos debates da Geografia, Human Territoriality é uma exposição da teoria de Robert David Sack. Nela, o autor trata sobre a territorialidade humana abordando aspectos conceituais e históricos a ela relacionados. Mas a obra não representa sua primeira incursão nas discussões sobre territorialidade e espaço. Doutor em Geografia pela Universidade de Minnesota e professor dessa disciplina e de Estudos Literários Integrados nas Universidades de Wisconsin e Madison, Sack já havia publicado, em 1980, a obra intitulada Conceptions of Space in Social Thought: a Geographic Perspective, na qual Sack apresenta a relação de dualidade das concepções e apropriações do espaço pela sociedade industrial e pelas sociedades primitivas.

Assim como não iniciou a relação do autor com a questão territorial, Human Territoriality também não a encerra, pois, após sua publicação, novos conceitos e teorias foram apresentados em obras como Place, Modernity and the Consumer's World: $A$ Relational Framework for Geographical Analysis (SACK, 1992) - nas quais discute as relações entre o consumo e suas implicações geográficas na criação e categorização de lugares - e Homo Geographicus: A Framework for Action, Awareness, and Moral Concern (SACK, 1997), que reúne uma coletânea de discussões sobre os conceitos de espaço e 
lugar e sobre a perspectiva humana acerca do mundo permeada por fatores como a natureza, a força dos significados e as relações sociais.

É possível notar que, ao longo da produção de Sack, a perspectiva de abordagem relacional do espaço sempre esteve presente. E, em Human Territtoriality, tal perspectiva se manifesta na abordagem da territorialidade humana como estratégia intencional de influência e controle espacial, teoria que acabou por influenciar muitas publicações sobre a temática territorial, tornando-se referencial neste campo de estudos, sobretudo no que se refere aos efeitos e desdobramentos da territorialidade.

Em Human Territoriality, ao iniciar a apresentação de seus conceitos e teoria, Sack (1986) afasta a territorialidade humana das disciplinas de caráter biológico que buscam explicar o conceito como uma espécie de instinto, comparado ao dos outros animais que demarcam e defendem seu território.

Segundo o autor, a territorialidade humana é, portanto, mais "sofisticada" do que uma mera manifestação instintiva. Ela é "[...] a tentativa de um indivíduo ou grupo de afetar, influenciar, ou controlar pessoas, fenômenos, e relações, delimitando e afirmando o controle sobre uma área geográfica" (SACK, 1986, p. 19).

Tal perspectiva se aproxima dos conceitos apresentados por Raffestin (1993), quando o autor afirma que o território não é tão somente o espaço físico, depósito material de recursos, mas é, sobretudo, o resultado de um programa intencional, isto é, da aplicação de energia e de informações para a implantação de estratégias adotadas por atores sintagmáticos - responsáveis pela elaboração e condução de um programa -, que produzem este território.

O território é, portanto, sistema físico e também sêmico (uma vez que comunicado pela linguagem e por símbolos), que permeia as relações entre as pessoas e o espaço, contribuindo para a definição dessas relações e também sendo definido por elas. Em um processo que é eminentemente relacional, o território se constitui na esfera de ação no qual, indivíduos e grupos exercem sua territorialidade, isto é buscam influenciar, ou mesmo controlar, pessoas, fenômenos e relações.

Assim, a simples demarcação ou delimitação de um espaço geográfico não caracteriza a existência de um território. Este último só se manifesta quando suas delimitações e fronteiras são utilizadas para moldar comportamentos e controlar o acesso a recursos e poder. Segundo Sack (1986, p. 19), "Diferentemente de outros tipos ordinários de lugar, territórios exigem constante esforço para o seu estabelecimento e manutenção".

É possível tecer linhas de contato entre o pensamento de Sack e a defesa da ideia do espaço como um "[...] conjunto indissociável de sistemas de objetos e de ações [...]", segundo conceito de Santos (2006, p. 12), que nos apresenta a imagem dos territórios como híbridos, constituídos de formas e conteúdos (inseparáveis), que vão muito além da simples 
presença e comunicação de fronteiras. A partir desse conceito de espaço, o autor elenca, inclusive, suas categorias de análise, incluindo a paisagem, a divisão territorial do trabalho, a técnica - como elemento que intermedia a relação entre o homem e os recursos materiais - e a intencionalidade que configura o espaço produzido ou produtivo. Com base na inseparabilidade dos objetos e ações, destaca-se a noção de intencionalidade no processo de criação, recriação e renovação dos lugares, em movimentos que tem na divisão do trabalho o "[...] motor da vida social e da diferenciação espacial" (SANTOS, 2006, p. 84).

As similaridades nas abordagens de Robert David Sack e de Milton Santos afastam o conceito de territorialidade de um sentido etológico, associado, na biologia, à demarcação de territórios e que, durante muito tempo, foi transferido para as ciências humanas, em uma postura classificada pelo próprio Milton Santos (2006, p. 264) como "perigosa e esterilizante".

Sack afirma que os territórios são formas construídas socialmente e que tantos as relações quanto os efeitos espaciais dependem dos propósitos de quem está controlando quem. Como afirma o autor, a "[...] territorialidade aponta para o fato de que as relações humanas no espaço não são neutras" (SACK, 1986, p. 26). A intencionalidade por trás das estratégias que configuram os territórios também ganha destaque na obra de Raffestin (1993, p. 144), quando esse autor afirma que “[...] o território se apóia no espaço, mas não é o espaço. É uma produção, a partir do espaço [...]”, e configura o resultado das ações intencionais conduzidas por atores sintagmáticos, que, ao se apropriarem do espaço de maneira concreta ou abstrata, "territorializam" o espaço (RAFFESTIN, 1993, p. 143).

Intencionalidade, construção social, estratégias e ações espaciais configuram elementos chave na tentativa de Sack (1986) de formular uma teoria sobre a territorialidade, processo no qual o autor não nega a sua expertise voltada à análise espacial como instrumento próprio da geografia social, uma vez que as atividades humanas ocorrem no espaço e tem propriedades espaciais. Como afirma Raffestin (1993, p. 164) "[...] entrar em relação com os seres e as coisas é traçar limites ou se chocar com limites. Toda relação depende da delimitação de um campo, no interior do qual ela se origina, se realiza e se esgota".

Sack (1986) também deixa claro que sua intenção é ocupar posição intermediária entre o ideal positivista do estabelecimento de relações axiomáticas - que podem ser usadas para prever o comportamento humano - e um mero apanhado de noções fracamente conectadas. O que ele chama de teoria é um grupo de características interrelacionadas que podem ser usadas para explicar ou dar sentido ao comportamento.

Em Human Territoriality o foco da análise remete às vantagens e desvantagens do uso da territorialidade, melhor entendida como uma estratégia espacial para afetar, influenciar ou controlar fenômenos e pessoas, a partir de um controle de área. Além disso, discute-se 
como a territorialidade é utilizada historicamente, manifestando-se de maneiras singulares em várias épocas, e que efeitos ela produz na organização social.

Enquanto estratégia e forma de comportamento social, a territorialidade humana exige consumo de energia e de informação para sua implantação e manutenção. Ela pode ser acionada ou "desligada" - dependendo de quem busca influenciar quem, em que condições e em que períodos. Por fim, e acima de tudo, ela produz vantagens e desvantagens, apresenta causas intencionais para as ações e produz efeitos territoriais. Alguns desses efeitos são universais, ocorrendo em cenários históricos e organizações sociais diversos, outros se limitam a períodos históricos ou tipos de organizações específicos. A sociedade moderna, por sua vez, tende a acionar toda a gama de possíveis efeitos territoriais (SACK, 1986).

Como escrito anteriormente, o território não é e nem pode ser considerado um local, e a diferença básica encontra-se no esforço necessário para estabelecer o território e na constância que o mesmo exige para ser mantido. Delimitar coisas em um mapa, por exemplo, é apenas identificar locais ou áreas e não produzir territórios. Usar estratégias para afetar, influenciar e controlar pessoas, fenômenos e relações através de uma delimitação e controle de área, isto sim produz um território. Desse modo, a territorialidade é também uma estratégia que estabelece diferentes níveis de acesso à pessoas, recursos e poder e, assim, pode ser colocada dentro do contexto das motivações humanas. Sem formas de controle sobre a área - com base em instrumentos e esforços territoriais e nãoterritoriais - as pessoas e suas formas de organização não encontrariam local no espaço.

Neste ponto, deve estar claro que a territorialidade é socialmente construída, com base em relações que não podem ser classificadas como neutras e que envolvem diversos níveis de razão e significados, apresentando, inclusive, aspectos normativos. Como afirma o próprio autor,

Pessoas não interagem e se movem no espaço como bolas de bilhar. A interação humana, o movimento e o contato são uma questão de transmissão de energia e informação com o objetivo de afetar, influenciar e controlar as ideias e ações de outros e o seu acesso a recursos. Relações humanas espaciais são resultado de influência e poder. A territorialidade é a forma espacial primária assumida pelo poder (SACK, 1986, p. 26).

Deixar alguns locais de lado, enquanto se reforça o controle de acesso a outros, implica em um processo de escolhas que remove ou inclui pessoas e atividades em determinados espaços, segundo estratégias intencionais. Na argumentação de Sack, a territorialidade relaciona-se intimamente com as formas pelas quais as pessoas usam o espaço e nele se organizam, isto é, como elas dão sentido ao lugar. 


\section{OS EFEITOS OU TENDÊNCIAS DA TERRITORIALIDADE}

É importante saber o que a territorialidade é, mas fundamental é entender o que ela faz, uma vez que o valor da definição de um fenômeno encontra-se justamente na possibilidade de criar suporte para a identificação e compreensão da importância dos seus efeitos. E, no caso da territorialidade, os três efeitos ou tendências básicas apontadas por Sack (1986) são: a classificação por área, a comunicação de fronteiras (ou limites) e o controle do acesso.

Classificar por área significa atribuir características comuns e, principalmente, parâmetros de controle a serem aplicados a determinados objetos e relações simplesmente porque eles se encontram em um mesmo espaço circunscrito. Assim, a territorialidade permite categorizar pessoas e coisas e submetê-las a influências e controles normativos sem que seja necessário discriminá-las por tipo. Basta que elas pertençam a um mesmo território.

Colocar as coisas em uma categoria em função de sua localização no espaço evita a necessidade de enumerar e caracterizar por tipo, o que pode ser o único meio de estabelecer e afirmar controle quando não é possível enumerar todas as variáveis e fatores significantes que fazem parte de um território.

Além disso, delimitar por área ao invés de enumerar por tipo facilita o esforço de afirmação dos limites, que não precisam ser vinculados a normas detalhadas, mas apenas à indicação direta que determina a linha que não pode ser ultrapassada e que define também o que pertence (está dentro) e o que não pertence (está fora) de uma delimitação espacial específica (SACK, 1986).

Para classificar por área, devem ser estabelecidos limites. Portanto, a territorialidade exige uma forma clara e assertiva de comunicação de fronteiras, definidas por quem controla e assimiladas pelos que são controlados.

Comunicar uma fronteira significa assinalar limites, o que pode ser feito, segundo Sack (1986), por meio de um marco, um sinal ou mesmo uma representação simbólica. Raffestin (1993, p.153) chega a afirmar que "Falar de território é fazer uma referência implícita à noção de limite que, mesmo não sendo traçado [...] exprime a relação que um grupo mantém com uma porção do espaço".

Se a ação espacial dos grupos não produzisse a delimitação, essa ação simplesmente se dissolveria. E é importante lembrar que, segundo Raffestin (1993, p. 170), “[...] os limites não são inocentes, nem naturais, muito menos arbitrários [...]. Eles fazem parte do nosso jogo de reprodução social [...]" e, uma vez que são vividos e consumidos, eles representam a expressão de nossa territorialidade. 
Associado à classificação por área e à delimitação, o controle do acesso veda a entrada dos elementos externos e controla e influencia as relações entre os elementos internos. Além disso, classificar por área, comunicar os limites e controlar o acesso são efeitos territoriais que, em conjunto, contribuem para que as relações se tornem impessoais e ajudam a moldar atividades em uma hierarquia. "Promover relações impessoais e atividades geograficamente moldadas dentro de uma hierarquia, são duas das muitas consequências identificáveis das três facetas da territorialidade, que seguem a partir desta definição" (SACK, 1986, p. 26).

Assim, é interessante destacar que, ao tratar da impessoalidade e das relações em sistemas hierarquizados, Sack (1986) faz referência à burocracia de Weber (2004), apresentando, como características das organizações capitalistas modernas, as linhas formais de comunicação, a hierarquia clara, as definições de autoridade, as relações impessoais, a especialização das atividades, a padronização e a formalização dos procedimentos.

Aos três efeitos primários da territorialidade, somam-se, de acordo com a teoria de Sack, mais sete efeitos ou tendências (não necessariamente apresentados nesta ordem pelo autor): reificação simbólica, deslocamento, multiplicação de territórios, relações impessoais, limpeza do espaço, o território como um container/molde (para as propriedades espaciais dos eventos) e o lugar conceitualmente vazio.

A reificação simbólica, segundo Sack (1986) diz respeito ao fato de que a territorialidade propicia meios para "reavivar o poder", isto é, tornar o poder visível e suas potencialidades explícitas e reais. A reificação simbólica aparece, por exemplo, em expressões do tipo "vestir a camisa", "defender a bandeira" e em outras expressões nacionalistas.

O deslocamento se refere ao uso da territorialidade para "desviar a atenção da relação entre controlador e controlado". Desta forma, a partir de afirmações legais e convenções do comportamento espacial que se tornam demasiadamente arraigadas nos indivíduos socializados - a ponto de serem desprezadas como elementos de controle - o "território parece ser o agente de controle", uma vez que a territorialidade inibe a avaliação crítica dessas afirmações legais (SACK, 1986). O território, a norma ou a convenção aparecem como o agente controlador, o que se verifica em expressões como "é a lei da terra" ou "essa prática não é permitida neste local". E, como escrito anteriormente, a territorialidade impede a avaliação crítica de tais afirmações pelos indivíduos.

A multiplicação de territórios se dá quando há uma sobreposição de eventos dentro dos limites de um território ou quando os eventos ultrapassam esses limites. Por outro lado, também há a necessidade de novos eventos que possam vir a ocupar territórios novos e 
vazios, assim, Sack (1986, p. 34) reforça que "[...] novos eventos precisam ser produzidos por territórios novos e vazios. A territorialidade tende a ser uma preenchedora de espaço."

Classificar por área, e não por tipo, permite tornar as relações impessoais, na medida em que a categorização se dá em função de propriedades espaciais. Tais relações impessoais - e também marcadas por uma hierarquia territorial - podem ser observadas, por exemplo, em ambientes como as prisões e empresas. Nas primeiras, um guarda é responsável pelo controle e vigilância de um bloco de celas - sem que se precise discriminar os indivíduos ali encarcerados -, e, nas segundas, os supervisores são responsáveis por várias linhas de montagem - também repletas de indivíduos que acabam não sendo reconhecidos por características particulares, mas apenas pelo fato de pertencerem àquela linha de montagem específica. Também é possível observar a tendência das relações impessoais nas escolas, onde os indivíduos são categorizados pela série que cursam ou sala que ocupam.

A territorialidade também pode ser acionada para fabricar um local limpo ou limpar o espaço para outras coisas existirem. E, para explicar a limpeza do espaço, Sack (1986, p. 33) escreve que "[...] as coisas precisam de espaço para existir [...]", portanto, é mais adequado falar de uma "[...] competição por coisas e relações no espaço [...]", do que de uma competição por espaço. E, segundo essa dinâmica, a territorialidade é o meio capaz de limpar o espaço, prepará-lo para que ele possa acondicionar coisas e relações, segundo estratégias e interesses específicos.

Assim, o território torna-se um container, um molde para as "propriedades espaciais dos eventos". E os atores sintagmáticos citados por Raffestin (1993) - do Estado ao indivíduo, passando pelas organizações de portes distintos - relacionam-se com o conjunto de fatores já existentes nesse container, que podem configurar elementos limitantes ou favoráveis e produzem, reconfiguram ou mesmo esvaziam conceitualmente os territórios, a fim de garantir a implantação de suas estratégias. E é válido observar que, se o campo político apresenta certa estabilidade, o campo econômico é muito mais dinâmico, fluido, e permite constantes adaptações a mudanças estruturais e conjunturais.

Se o território é um container e a territorialidade permite alocar e realocar coisas e eventos nessa espécie de moldura, essa mesma territorialidade contribui para criar a ideia de um lugar conceitualmente vazio - e, por consequência, preenchível. Se o lugar é desprovido de coisas de valor econômico e/ou social (que o poder deseja controlar), ele é considerado vazio ou pode ser esvaziável. Separando, em nível conceitual, o lugar e as coisas, a lógica territorial pode combiná-los e recombiná-los estrategicamente. O conceito de lugar vazio aparece em expressões como "lote vazio", "área desabitada", "terreno desocupado", "zonas degradadas" e "áreas urbanas envelhecidas". Assim, o espaço esvaziável torna-se um componente importante da modernidade e a territorialidade mantém 
sua função de "[...] preencher, esvaziar e rearranjar continuamente coisas em um território, com o propósito de um controle funcional eficiente" (SACK, 1986, p. 37).

\section{AS COMBINAÇÕES TERRITORIAIS}

A partir das relações que se estabelecem entre as sete tendências da territorialidade, com base em níveis diversos de interação, Sack (1986) apresenta quatorze combinações territoriais.

Assim, combinações específicas se originam de conjuntos distintos de tendências territoriais e de intensidades na manifestação de cada uma dessas tendências. Desse modo, uma mesma combinação pode apresentar tendências que se configuram como mais importantes e decisivas e outras que, embora tenham o seu grau de participação, apresentam uma menor relevância.

Nesse sentido, a obra de Robert David Sack apresenta uma ilustração, reproduzida na Figura 1, que facilita muito, em termos didáticos, a compreensão das relações - e níveis de intensidade das mesmas - entre os efeitos da territorialidade e as combinações que se manifestam a partir das interações desses efeitos.

Para identificar os níveis de intensidade e de participação de cada tendência para cada uma das combinações territoriais, Sack lança mão de um recurso visual que simplifica a compreensão de seu modelo. Assim, o autor usa quadros com linhas diagonais para indicar que a tendência é importante na configuração da combinação, enquanto quadros em negrito indicam extrema relevância da tendência.

É importante destacar que os quadros em branco não indicam ausência de relação, mas sim baixa intensidade, isto é, uma baixa participação da tendência na configuração de uma combinação territorial específica. Assim como na apresentação dos efeitos territoriais, as combinações também não serão dispostas necessariamente na mesma ordem estabelecida por Sack em sua obra.

A não utilização da mesma disposição ordenada de combinações do autor original se justifica pela tentativa didática de estabelecer uma sequência de apresentação das combinações territoriais que facilite a sua compreensão, aproximando combinações cujas características se relacionem mais fortemente ou que contribuam de maneira conjunta ou complementar, para impactos específicos no contexto moderno.

Embora a ordem de exposição das combinações não seja a mesma adotada por Sack, as letras entre parênteses, que aparecem após o nome de cada combinação, correspondem às mesmas letras atribuídas pelo autor, possibilitando, assim, a identificação da combinação na Figura 1. 
Figura 1- Links Internos entre Tendências e Combinações Territoriais

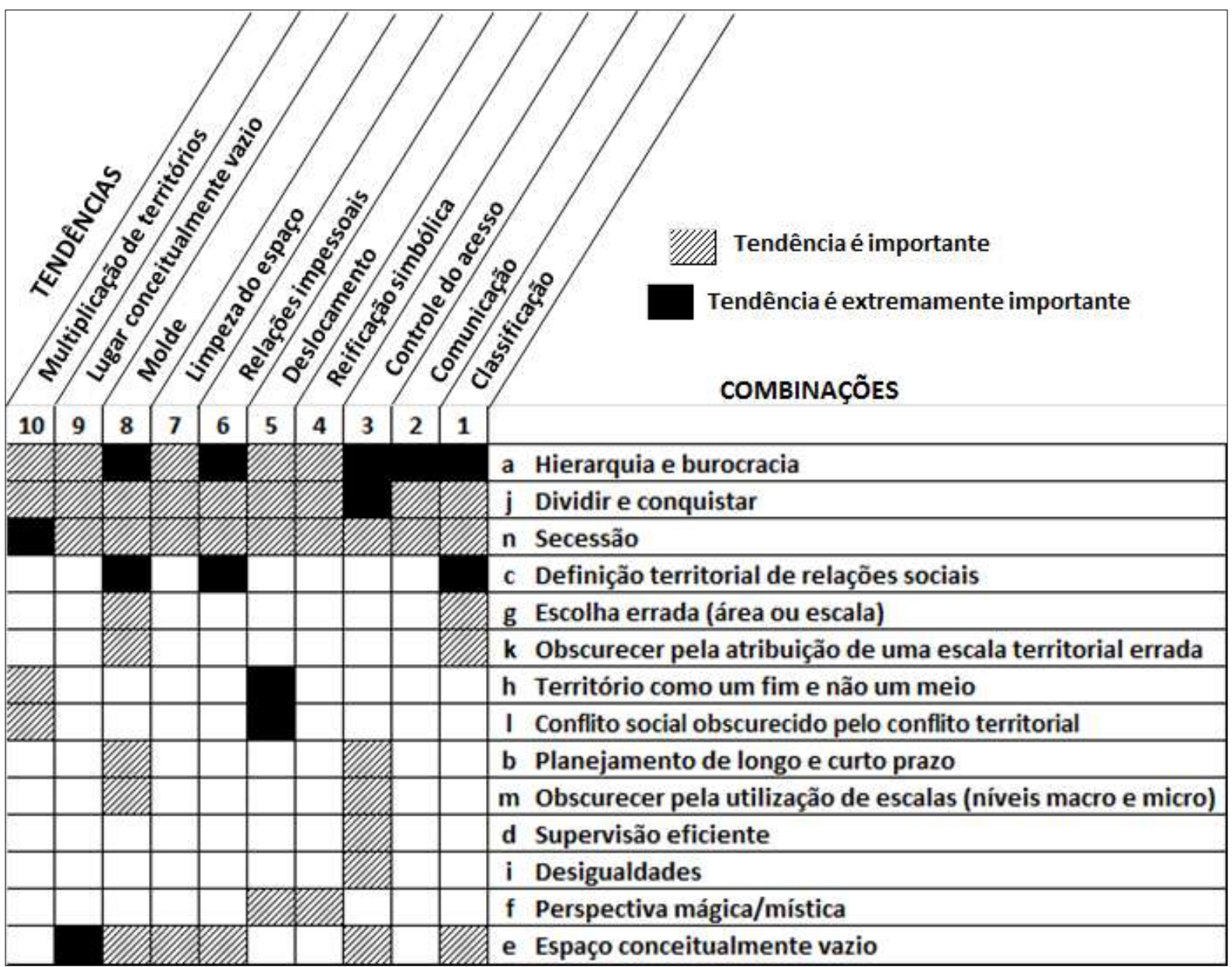

Fonte: adaptado de Sack (1986).

As relações hierárquicas e a burocracia (a), que derivam, em elevados graus de intensidade, de todas as tendências territoriais - com destaque para a classificação, comunicação, controle de acesso, relações impessoais e molde - são elementos de gestão organizacional que permitem circunscrever, inclusive espacialmente, o acesso a níveis distintos de conhecimento e de responsabilidade.

Basta observar os ambientes departamentalizados das empresas e instituições de diferentes segmentos de atuação para verificar tal realidade. Hierarquia e burocracia estão intimamente relacionadas com a configuração de um ambiente em que imperam relações funcionais e impessoais, que se manifestam em linhas claras de autoridade e subordinação, controles padronizados e canais formais de comunicação.

As mesmas tendências capazes de produzir organizações burocráticas e hierarquizadas - com destaque para o controle do acesso - também podem ser acionadas para dividir e conquistar (j).

Para otimizar a coordenação de vários setores de uma empresa, por exemplo, cada um deles fica sujeito a um nível de controle do acesso à informação e responsabilidade. $O$ 
processo de dividir para conquistar torna a organização entrincheirada e, sobretudo nas instituições marcadas pela burocracia, torna-se indispensável para a coordenação das partes (SACK, 1986). Dividir e conquistar também podem ser os passos adotados para desarticular estruturas vigentes, a fim de criar outras, o que pode ocorrer no contexto organizacional ou em outras configurações sociais.

Novamente, todas as tendências territoriais - com destaque para a multiplicação de territórios - podem promover a redução do controle ou mesmo a secessão (n). Isso quer dizer que as mesmas ações territoriais que buscam dividir para conquistar, através do estabelecimento de um controle hierárquico efetivo, podem também provocar deslocamentos, resistência e oposição, levando, então, ao arrefecimento dos instrumentos de controle e a rupturas.

É o que acontece, por exemplo, quando grupos de trabalhadores reagem de maneira conflituosa ao grau de alienação imposto pelos instrumentos burocráticos. Dividir, conquistar e tornar as relações impessoais podem se constituir em excelentes instrumentos de controle e coordenação, mas, em determinados níveis, podem também criar desorganização, alienação, resistência e hostilidade (SACK, 1986).

Assim, segundo a teoria de Sack, fica claro que as situações de perda de controle ou secessão decorrem dos efeitos inversos da tentativa de obtenção de um controle hierárquico efetivo. $E$ os que resistem ao controle podem fazer uso dos territórios existentes, de modo que as lutas e conflitos se revestem de uma natureza territorial.

Classificação, relações impessoais e molde podem levar a uma definição territorial de relações sociais (c). Os níveis superiores das organizações sociais tendem a usar a territorialidade para definir e afirmar limites, moldar grupos e comportamentos e, dessa forma, transformar a lógica de definição social do território em uma lógica de definição territorial das relações sociais. E é válido dizer que ambas as lógicas podem ser encontradas no mesmo local e que, se a sociedade primitiva fundamenta-se mais na definição social, as sociedades modernas fundamentam-se com mais intensidade na definição territorial.

Nas organizações modernas, por exemplo, marcadas por relações impessoais, não são mais os laços sociais que definem a territorialidade, mas sim os espaços métricos e abstratos que definem áreas específicas, setores, departamentos ou mesmo unidades organizacionais.

É interessante ressaltar que, embora na Figura 1 não esteja destacada a tendência controle do acesso como uma das componentes dessa combinação, no text Sack atribui a ela o mesmo grau de importância das que foram destacadas.

A escolha errada de área ou escala (g) - preponderantemente afetada pela classificação e pelo molde - pode ser observada em organizações complexas, quando há 
uma distribuição errada (ou mal planejada) de conhecimento e responsabilidade, o que pode levar a falhas no processo de solução de problemas, na eficácia dos instrumentos de controle e na mediação de conflitos.

Neste caso, aqueles que controlam o poder podem se entrincheirar ainda mais na hierarquia e na burocracia, aumentando o peso dos controles formais à medida que diminuem a própria eficácia desses controles o que intensifica a alienação e, como visto anteriormente, pode levar a rupturas e secessão.

A classificação e o molde também podem obscurecer pela atribuição de uma escala territorial errada (k), que passa a ser percebida como adequada. É o que acontece, por exemplo, quando o controle da poluição é atribuído a um nível de governo local quando a questão, na verdade, é nacional.

O deslocamento (com maior intensidade) e a multiplicação de territórios podem levar aqueles que buscam exercer o controle a ver o território como um fim e não como um meio (h). Foi o que aconteceu no século V D.C, com a Igreja Católica como relatado pelo próprio Sack, quando o poder do arcebispo era proporcional ao número de dioceses e paróquias sob o seu controle. Assim, os arcebispos dividiam o território com a única finalidade de obter mais poder. Vale lembrar que o autor deixa bem claro que o território apenas aparece como fim "[...] porque a territorialidade como estratégia é sempre um meio para um fim" (SACK, 1986, p. 39).

Outra combinação que emerge do deslocamento e da multiplicação de territórios é a possibilidade de obscurecer o conflito social com base no conflito territorial (I). Nesse caso, relações conflituosas que tem origem em elementos socioeconômicos são camufladas pelo discurso territorial: o rural versus o urbano; o centro versus a periferia.

O planejamento de longo e de curto prazo (b) é uma combinação territorial diretamente relacionada com o controle do acesso e com o molde. Mais uma vez, os itens essenciais de controle são a informação e a responsabilidade. Nas organizações, os níveis superiores, com maior acesso à informação, são responsáveis pelo planejamento de longo prazo (geral e normativo), enquanto os níveis inferiores possuem como atributo o planejamento de curto prazo (marcado por detalhamentos e execução das tarefas). Sendo o longo prazo um atributo dos níveis superiores, eles passam a controlar o conhecimento e a responsabilidade, enquanto cabe aos níveis inferiores a simples execução de tarefas, baseadas em estratégias que eles sequer conseguem reconhecer e avaliar com algum critério.

Obscurecer pela utilização de escalas $(m)$ tem como tendências preponderantes 0 controle do acesso e o molde e, mais uma vez, as escalas de conhecimento e responsabilidade são vitais. O conhecimento total das ações e, por consequência, de seus 
impactos, fica a cargo de um nível superior, enquanto aos níveis inferiores são atribuídas execuções que não revelam o contexto maior.

Um grande investimento de capital, por exemplo, pode ser apresentado como positivo para níveis locais, de modo a obscurecer os impactos negativos, para atender uma lógica global. A definição dos locais para a criação de penitenciárias, lixões e barragens, por exemplo, é definida em nível macro e apresentada como escolha adequada, mesmo que os impactos de tal escolha se manifestem, de fato, em nível micro, isto é, local.

A territorialidade, com base no controle do acesso, permite aumentar o controle do espaço e torna a supervisão eficiente (d). Isso significa dizer que é possível, com base em configurações territoriais, reduzir o span of control, termo que designa o número de supervisores por supervisionados.

Reduzir o span of control torna possível utilizar um número menor de supervisores para controlar e supervisionar um número maior de supervisionados, como é o caso das prisões e das linhas de produção em grandes indústrias, por exemplo, onde o arranjo espacial permite que uma única pessoa supervisione vários indivíduos.

Para apresentar a próxima combinação territorial, é preciso reforçar que a territorialidade, como estratégia conduzida por agentes que Raffestin (1993) chama de atores sintagmáticos, ou seja, aqueles que, intencionalmente, combinam elementos para produzir uma ou várias coisas - inclusive territórios -, está baseada no controle do acesso diferenciado a recursos.

Assim, estabelece-se um processo de caráter segregacionista, uma vez que, em função dos seus interesses, os atores sintagmáticos produzem centralidades, cuja correspondência direta é a formação das periferias, que se inserem nas estratégias em curso e sofrem seus impactos - assim como sofrem tais impactos os atores paradigmáticos. Desse modo, o acesso diferenciado aos recursos promove desigualdades (i), reforçadas pelas estratégias territoriais.

O deslocamento e a reificação simbólica podem imputar ao território uma perspectiva mágico-mística (f), como se o próprio território constituísse fonte de autoridade e origem do poder.

No catolicismo, por exemplo, a estrutura física da igreja (visível) pode ser tomada por fiéis como a fonte do poder e não a fé (invisível). Algo semelhante, em termos de dinâmica territorial acontece com o nacionalismo. Segundo Sack (1986, p. 38), "[...] a fidelidade ao território ou à terra natal faz com que o território apareça como fonte de autoridade".

A tendência do lugar conceitualmente vazio (em maior intensidade), a classificação por área, o controle do acesso, as relações impessoais, a limpeza do espaço e o molde contribuem para a criação das burocracias modernas, para a hierarquização das relações e para a combinação de efeitos da territorialidade que não só constitui elemento 
extremamente importante da modernidade, mas, sobretudo, torna-se a principal variável territorial a acompanhar o surgimento do capitalismo: o espaço conceitualmente vazio (e).

De acordo com a ideia ocidental do progresso, "[...] a mudança e o futuro são vistos como setas de configurações espaciais" (SACK, 1986, p. 38) e, para que possa não só aumentar a eficácia de seu controle funcional dos espaços, mas também reforçar a mobilidade de pessoais, coisas e eventos, ratificando a necessidade da mudança e afrouxando os laços entre acontecimentos e território, o capitalismo precisa "[...] preencher, esvaziar e rearranjar continuamente" (SACK, 1986, p. 37) coisas em territórios métricos e abstratos. Esses territórios passam a configurar molduras úteis para o enquadramento de eventos e relações, que atendem a uma lógica de expansão do consumo, associada a um padrão de utilização intensiva de recursos.

O capitalismo, portanto, reforça o espaço como suporte para locação e distribuição dos eventos, ou seja, suporte local de instalações. A mudança torna-se um valor superior para atender a lógica da acumulação de capital, criando uma relação fluida entre as coisas e o espaço. O autor, na análise pela perspectiva histórica, reforça que:

No surgimento das civilizações, os efeitos mais importantes da territorialidade são os seus usos para o governo de outros, para definir relações sociais, para dividir, subjugar e para organizar populações. O efeito territorial mais importante que acompanha o surgimento do capitalismo são os seus usos para criar espaços conceituadamente vazios, burocracias modernas e camuflar as fontes do poder (SACK, 1986, p. 50).

Ainda que a configuração do território como uma moldura espacial, propícia para arranjar e rearranjar coisas e relações tenha reflexos em todas as escalas, é importante notar que a configuração de um espaço conceitualmente vazio acontece de maneira diferenciada em níveis micro e macro. Neste último, mais afeito à arena política, os novos territórios são vistos por Sack (1986, p. 172) como "grades espaciais abstratas" a serem preenchidas, uma vez que se encontram conceitualmente vazias. Foi o que aconteceu com a descoberta do Novo Mundo, quando os europeus simplesmente desconsideraram a presença dos nativos, tida como selvagens, na repartição e organização dos seus territórios métricos em uma vasta e ainda inexplorada - pelo menos pelos povos europeus - superfície geográfica.

Já no nível micro, o que ocorreu foi a substituição de um tumultuado mix de eventos (característica própria de um período pré-moderno) que se dava em um mesmo espaço - a casa e o local de trabalho, por exemplo, onde várias atividades e relações funcionais se desenrolam em um mesmo ambiente - por uma espécie de diminuição, marcada por subdivisões funcionais que criam ambientes específicos (containers) para apenas um tipo de coisa ou de atividade. 
É claro que tal movimento, facilmente observado pela divisão de cômodos em uma casa ou pela departamentalização de um local de trabalho, leva à delineação de novos territórios, que guardam como características comuns o fato de que são esvaziáveis; preenchíveis ou parceláveis. Assim, como nos mostra Sack (1986), o espaço da política começou como vazio e foi preenchido e o espaço do trabalho foi reduzido e então esvaziado.

Em ambos os níveis de análise (micro e macro), independentemente das diferenças do processo de configuração do espaço conceitualmente vazio, é possível notar a presença da multiplicação de territórios e a intensificação das hierarquias e das relações impessoais e burocráticas.

$E$, à medida que tais características se manifestam e a relação entre eventos e território se torna cada vez mais contingencial, diferentes porções de espaço podem ser caracterizadas em função do seu valor para o sistema econômico vigente. Assim, espaços produtivos ou que reúnem recursos cuja exploração interessa aos agentes capitalistas são tidos como "áreas de esforço", "teatro das operações", enquanto espaços que não reúnem recursos ou características interessantes são "lugares desperdiçados", "territórios improdutivos" ou simplesmente "lugares vazios" (SACK, 1986).

Como aponta Santos (2006, p. 88): "Essa divisão territorial do trabalho cria uma hierarquia entre lugares e, segundo a sua distribuição espacial, redefine a capacidade de agir de pessoas, firmas e instituições".

É possível notar, portanto, que, a partir do advento das civilizações modernas, da expansão do capitalismo e da supremacia de uma abordagem científica e tecnológica das atividades humanas - sobretudo das atividades de trabalho -, configura-se na prática a ideia do constante esvaziamento e preenchimento dos territórios, em função do constante e cada vez mais intenso movimento de coisas em todas as escalas.

Forma-se, então, uma parceria, em uma espécie de dinâmica de suporte recíproco, entre o espaço métrico abstrato e as necessidades de uma economia de consumo baseada na produção em massa.

O espaço abstrato torna-se uma moldura prática e de fácil manipulação para um sistema que atende a lógica capitalista de expansão e acumulação, ao mesmo tempo em que afrouxa as ligações entre pessoas, eventos e lugares.

E o mais irônico, como aponta Sack (1986), é que nós tentamos restabelecer as raízes que nos ligam aos lugares através do próprio consumo, que a propaganda nos apresenta como o gatilho para criar um contexto significativo para as nossas vidas imersas em espaços métricos e sem significância, criados, fragmentados e tornados abstratos pelo próprio ato de consumir. 
E toda essa dinâmica de consumo, mobilidade e esvaziamento dos espaços se intensifica em sociedades inseridas em contextos dominados pela técnica, ciência e informação. Se a compreensão do território se dá a partir dos seus usos, como sugerem Santos e Silveira (2006, p. 28), com base nos sistemas técnicos - formas híbridas compostas por "sistemas de objetos" e "sistemas de ações" - que mediam as relações das pessoas com o espaço geográfico, é possível dizer, de acordo com os mesmos autores, que vivemos em um "meio técnico-científico-informacional" que reforça a fluidez dos elementos. Basta notar que os dois recursos mais fluidos das atuais relações econômicas - a informação e as finanças - passam a "[...] configurar a nova geografia, distinguindo os lugares segundo a presença ou escassez das novas variáveis-chave".

Destaca-se, portanto, que, na teoria de Sack (1986), a constante manipulação de coisas em um território leva a uma separação conceitual entre os eventos e o espaço. Assim, a territorialidade, como estratégia intencional, torna-se um recurso capaz de manter o espaço conceitualmente esvaziável e, por consequência, preenchível. Tal dinâmica tornase ainda mais intensa em um meio dominado pelas relações capitalistas e impregnado de ciência e tecnologia - o meio técnico-científico-informacional, como destaca Santos (2006), onde a ideia de esvaziamento e preenchimento, de forma repetida e sempre eficiente em relação às estratégias planejadas, torna cada vez mais frenético o movimento e o potencial de mobilidade das coisas, em todas as escalas.

Com base em uma análise geral da modernidade, Sack (1986) aponta o passado recente e o presente como os momentos em que mais se deve esperar o aumento de frequência e a intensificação do conceito de espaço esvaziável. Desse modo, o capitalismo contribuiu para converter o espaço em commodity. E, se na lógica do progresso, o crescimento deriva da mudança, mudar passa a ser imperativo e significa uma relação cada vez mais fluida entre as coisas e o espaço.

Afrouxar ou arrefecer os laços e vínculos entre eventos e locais contribui para a constante movimentação, organização e reorganização de coisas e de pessoas no espaço, assim como torna o território pano de fundo métrico e abstrato, marcado por relações impessoais, fluidas e hierarquizadas.

É importante, ainda, destacar o fato de que a fluidez é sempre relativa. Assim, um território pode ser comparado a outros ou a sua situação atual comparada a momentos anteriores. Estabelece-se, portanto, não só uma relação contingencial entre eventos e espaço, mas também uma hierarquia de locais mais ou menos atrativos em função de seus recursos e diferenciais competitivos (SANTOS, 2006).

Diante de tal cenário, os atores sintagmáticos organizacionais - sobretudo as grandes corporações - usam a territorialidade para moldar os espaços, que podem ser esvaziados e preenchidos, segundo estratégias específicas. As organizações adotam, portanto, uma 
postura que reduz o território ao status de moldura manipulável e, ao mesmo tempo em que garantem relações capazes de impulsionar a sua dinâmica de acumulação de lucros no curto prazo e de exploração intensiva dos recursos, tornam as ligações entre eventos, pessoas e locais cada vez mais efêmeras, o que torna as relações fluidas, impessoais e submetidas a uma hierarquia de valores.

\section{CONSIDERAÇÕES FINAIS}

Citada de maneira superficial em várias produções científicas que tratam do estudo do território e ainda não traduzidas oficialmente para o português, a obra Human Territoriality: Its theory and history, de Robert David Sack, acrescenta às abordagens de análise científica do território e da territorialidade, uma teoria impactante com informações que apresentam o território como sistema físico e sêmico, socialmente construído. Assim, o território não é simples espaço delimitado, mas a esfera de ação onde indivíduos e grupos exercem sua territorialidade, ou seja, buscam influenciar ou controlar pessoas, fenômenos e relações.

A territorialidade passa a ser entendida, então, como estratégia espacial de controle e influência, marcada por intencionalidade por parte dos atores que a acionam. Desse modo, a teoria de Sack guarda semelhanças conceituais com as análises de Raffestin e Milton Santos, e acrescenta conteúdos relacionados aos efeitos que a territorialidade produz sobre a organização social dos espaços.

A maneira como o autor reforça a importância não só de se definir a territorialidade, mas, sobretudo, de entender o que ela faz com a apresentação das dez tendências e das quatorze combinações de tendências da territorialidade - centro da teoria de Sack -, com a associação de exemplos históricos e práticos aos argumentos conceituais, leva à construção de um cenário de análise que, sem dúvida, contribui muito para o enriquecimento das abordagens científicas sobre o território e a territorialidade, não deixando dúvidas de que os conteúdos abordados pelo autor são muito mais profundos do que o conceito de territorialidade apresentado já na introdução ou no primeiro capítulo de sua obra, tão reproduzido por outros autores que se aventuram a falar sobre território.

Por último, é importante salientar como uma combinação específica de tendências da territorialidade, o espaço conceitualmente vazio, representa a faceta territorial que se relaciona tão intimamente com algumas variáveis que nos são tão próximas em nosso contexto social e que se intensificam desde o início da modernidade e o surgimento do capitalismo. Entre elas, podemos destacar: a mudança como prerrogativa da ideia ocidental de progresso, a dissociação entre eventos e território, as relações impessoais, o aumento da mobilidade das pessoas e coisas e a percepção do espaço como moldura manipulável para a organização e reorganização contínua de coisas e relações. Todas essas variáveis, de 
alguma forma, ajudam a definir e são definidas por uma territorialidade humana que se manifesta como estratégia espacial de influência e controle.

\section{REFERÊNCIAS}

DELEUZE, G.; GUATTARI, F. A thousand plateaus: capitalism and schizophrenia. Minneapolis: University of Minnesota Press, 2005.

DELEUZE, G.; GUATTARI, F. O anti-Édipo: capitalismo e esquizofrenia. São Paulo: Ed. 34, 2010.

DELEUZE, G.; GUATTARI, F. O que é a filosofia? Rio de Janeiro: Ed. 34, 1992.

GUATTARI, F.; ROLNIK, S. Micropolítica: cartografias do desejo. Petrópolis: Vozes, 1996.

HAESBAERT, R. Da desterritorialização à multiterritorialidade. Boletim Gaúcho de Geografia, Porto Alegre, v. 29, n. 1, p. 11-24, 2003.

HAESBAERT, R. O mito da desterritorialização: do "fim dos territórios" à multiterritorialidade. Rio de Janeiro: Bertrand Brasil, 2004.

HAESBAERT, R. Território e multiterritorialidade: um debate. Geographia, Niterói, ano 9, n. 17, p. 19-45, 2007.

HAESBAERT, R. Territórios alternativos. São Paulo: Contexto, 2002.

HAESBAERT, R. Viver no limite: território e multi/transterritorialidade em tempos de insegurança e contenção. Rio de Janeiro: Bertrand Brasil, 2014.

LEPETIT, B. Por uma nova história urbana. São Paulo: Universidade de São Paulo, 2001. MASSEY, D. Pelo espaço: uma nova política da espacialidade. Rio de Janeiro, Bertrand Brasil, 2008.

RAFFESTIN, C. Por uma geografia do poder. São Paulo: Ática, 1993.

SACK, R. D. Homo geographicus: a framework for action, awareness, and moral concern. Baltimore: Johns Hopkins University Press, 1997.

SACK, R. D. Human territoriality: its theory and history. London: Cambridge University Press, 1986.

SACK, R. D. Place, modernity, and the consumer's world: a relational framework for geographical analysis. Baltimore: Johns Hopkins University Press, 1992.

SANTOS, M. A natureza do espaço: técnica e tempo, razão e emoção. São Paulo: Universidade de São Paulo, 2006.

SANTOS, M.; SILVEIRA, M. L. O Brasil: território e sociedade no início do século XXI. Rio de Janeiro: Record, 2006.

SAQUET, M. A. Abordagens e concepções de território e territorialidade. Revista Geográfica de América Central, Heredia, v. 2, p. 1-16, 2011.

SAQUET, Marcos Aurélio. Abordagens e concepções de território. São Paulo: Expressão Popular, 2007.

SAQUET, M. A. Proposições para estudos territoriais. Geographia, Niterói, v. 8, n. 15, p. 71 85, 2006.

WEBER, M. A ética protestante e o "espírito" do capitalismo. São Paulo: Companhia das Letras, 2004. 